\title{
KOSMOSE LOOMISE/TEKKIMISE MÜÜDID LÄHIS-IDAS
}

Peeter Espak

\begin{abstract}
TEESID: Artikkel analüüsib muistseid sumeri loomismüüte, kus maailma tekkimist või loomist kirjeldatakse peamiselt kui meessoost taevajumala An'i ja naissoost maajumala Ki suguakti tulemit. An ja Ki asuvad ühtesse, misjärel Ki jääb rasedaks ja sünnitab mitmed teised sumeri tähtsad jumalused - nende hulgas ka kuujumal Su'eni ja päikesejumal Utu. Analüüsitud müütide hulgas on varadünastilised ( $c$ a 24. saj eKr) Bartoni silinder ja müüdifragment nimega Urukagina 15. Uus-sumeri müütidest on vaatluse alla võetud inimeseloomismüüt „Enki ja Ninmah“ ning eepilis-müütiline lugulaul „Gilgameš, Enkidu ja allilm“. Võrdlevate näidetena on toodud paralleele ka Vana Testamendi Genesise loomismüüdiga; uut tüüpi ja inimesele vabanemist pakkuva Lähis-Ida loomismüüdina on esitatud Johannese evangeeliumi algus. Artikkel lõpeb arvamusega, et ka tänapäevane füüsikaline loomismüüt Suurest Paugust on kõigest mütoloogiline viis maailma kirjeldamiseks, mis ei erinegi oma olemuselt väga palju kõige varajasematest sumeri müütidest, kuigi on lähedasem teatavale objektiivsele tõelisuse printsiibile.
\end{abstract}

MÄRKSÕNAD: sumeri mütoloogia, Lähis-Ida usundid, loomismüüdid, müüt „Enki ja Ninmah“, eepilis-müütiline lugulaul „Gilgameš, Enkidu ja allilm“, Bartoni silinder, Ukg 15

Sumeri mütoloogilised tekstid algavad sageli sissejuhatava osaga, kus on kirjeldatud tänapäevase maailma teket. Müütides, mille sissejuhatuses on mainitud alguses maailma loomist, ei peatuta sel teemal hiljem enam pikemalt ning säärased sissejuhatavad lõigud on tõenäoliselt kasutusele võetud esmalt seetõttu, et anda müüdile teatav alguspunkt, ja ühtlasi ka selleks, et juurde lisada tõsiseltvõetavust või siis lihtsalt põnevust. Tegemist 
on kirjandusliku võttega - mingi rahva teadvuses olev arusaam maailmakõiksuse tekkest on lisatud juba täiesti uue kirjandusteose illustreerimiseks või siis raamimiseks. Lihtsustatult võiks öelda, et sellist kirjanduslikku võtet on alati kasutatud ja kasutatakse ka tänapäeval kas või muinasjututekstide algusfraasides, näiteks nagu „Ükskord ennemuistsel ajal“. Jan van Dijk (1965, 1976) ongi sellist viisi sumeri müüdi sissejuhatuses kutsunud in illo die ${ }^{1}$-motiiviks. ${ }^{2}$

Huvitaval kombel ei ole säilinud hilisemaid sumeri ega ka akkadi tekste, mis selgesõnaliselt kirjeldaksid kosmose loomist või siis tekkimist. Mõningast teavet hilisemate semiidi rahvaste arusaamadest pakuvad küll näiteks loomismüüt „Enuma eliš“ ja tekst pealkirjaga „Maailmaloomine Marduki poolt". ${ }^{3}$ Vanematest tekstidest 3. aastatuhandest eKr on praeguseks teada vaid raskestimõistetavad müüdifragmendid, nagu näiteks Ukg 15 kuningas Uru'inimgina ajastust 24. saj eKr. ${ }^{4}$ Hilisemad uus-sumeri müüdid nagu „Enki ja Ninmah“ ei peatu enam aga kõikide asjade alguse motiivil pikemalt ning maailma loomine leiab äramärkimist ainult lühida sissejuhatava motiivina. Säilinud ei ole ka ühtegi arutelu ega müüti sumeri või akkadi keeles, kus oleks kirjeldatud seda, millises olekus oli maailm enne taeva ja maa loomist või kes oli taeva ja maa loojaks. Pikemalt kirjeldatakse küll looduse ja inimtsivilisatsiooni teket ja ka maailmakorda määravate reeglite paikapanemist. Müüdid võivad seletusi anda isegi igapäevaelu pisiasjadele, kuid maailma tekkimisest või loomisest pikemalt ei räägi. On lihtsalt paari lausega mainitud, et kunagi ennemuistsel ajal loodi või siis tekkisid taevas ja maa. Jan van Dijk (1965: 13) on mõningatele tekstidele tuginedes küll üritanud väita, et teatavas sumeri mõttemaailma kihistuses võis olla levinud arusaam nn ,ennemuistsest linnast“, kus nii taevas kui maa, teised jumalused, taevakehad ja üleüldse kõik maailma- ja kultuurinähtused elutsesid embrüonaalses olekus. Ehk kõik hiljem avalduv oli juba idee ja mõttena igavesest ajast igavesti olemas. Embrüonaalolekus maailm sai aga reaalsuseks tänapäevase maailma kujul sellest, et ühel hetkel hakkasid meessoost taevas An ja naissoost maa Ki sugu tegema. Ki jäi selle suguakti tulemusel rasedaks ning sündisid kõik suured sumeri jumalused. See rasedus ja hilisem sünnitus viisid aga embrüonaalolekus koos olnud ürgjumalused taeva ja maa üksteisest lahku. Nende kahe vahel olevast ruumist sai tänapäevane inimeste maailm, kus hakkas elama loodus, tekkis jumalate ja inimest tsivilisatsioon. Osa jumalusi jäid

${ }^{1}$ Ld 'sellel päeval'.

${ }^{2}$ Seda teemat on analüüsinud ka Eesti Assürioloogia Seltsi liige ja Tartu Ülikooli audoktor Manfried Dietrich (1995).

${ }^{3}$ Ülevaateks: Espak 2010: 165-174; Clifford 1994.

${ }^{4}$ Selle teksti kommenteeritud väljaanne eesti keeles: Espak 2005 ja 2009. 
allilmadesse (Kur, Abzu), teised aga taevastesse sfääridesse (vt lisaks Horowitz 1998).

\section{BARTONI SILINDER}

Üks vanimaid sumeri tekste, kus esineb An'i ja Ki kosmilise abielu motiiv kui müüdi sissejuhatus, on Nippuri linnast leitud tekst, mida kutsutakse teksti leidnud arheoloogi nime järgi Bartoni silindriks. Tekst ise pärineb suure tõenäosusega kas varadünastilise Sumeri ajastu lõpust või siis varajasest sargoniidide Akkadi ajastust - seega kirja pandud ajavahemikul ca $2400-2300 \mathrm{eKr}$.

\begin{tabular}{|c|c|}
\hline $\begin{array}{l}\mathrm{u}_{4}-\text { rí-a } \mathrm{u}_{4} \text {-rí-šè } \\
\text { na-nam }\end{array}$ & $\begin{array}{l}\text { Neil kaugeil päevil, neil päevil, mis kauged } \\
\text { tõesti olid }\end{array}$ \\
\hline$g i_{6}$-rí-a gi ${ }_{6}$-rí-šè & Neil kaugeil öil, neil öil, mis kauged \\
\hline na-nam & tõesti olid \\
\hline $\begin{array}{l}\text { mu-rí-a mu-rí-šè } \\
\text { na-nam }\end{array}$ & $\begin{array}{l}\text { Neil kaugeil aastail, neil aastail, mis kauged } \\
\text { tõesti olid }\end{array}$ \\
\hline $\mathrm{u}_{4} \mathrm{na}-\mathrm{du} \mathrm{u}_{7}-\mathrm{du} \mathrm{u}_{7}$ & Torm möllas \\
\hline nin na-gír-gír & välgud sähvisid (?) \\
\hline èš nibruki & Nippuri templi (juures) \\
\hline $\mathrm{u}_{4} \mathrm{na}-\mathrm{du}_{7}-\mathrm{du}_{7}$ & Torm möllas \\
\hline nin na-gir-gir & välgud sähvisid (?) \\
\hline an-né ki-da & An (taevas) Ki'ga (maaga) \\
\hline inim an- $\mathrm{dab}_{6}-\mathrm{e}$ & rääkis \\
\hline
\end{tabular}

Kahjuks järgnevad 7 rida Bartoni silindrist ei ole säilinud ja võib ainult oletada, milliseid sündmusi müüt edasi kirjeldab. Kuna müüt jätkab looga sellest, kuidas keegi jumalus (oletatavasti Enki) teeb sugu sumeri ühe peamise jumaluse Enlili õe Ninhursagiga (Michalowski 1998: 240), võiks arvata, et hävinenud teksti osas on kirjeldatud seda, kuidas sündisid või tekkisid sumeri tähtsamad jumalused - Enki, Enlil ning ka Su'en ja Utu - kuu ja päike.

\section{UKG 15}

Lagaši riigi kuningas Uru'inimgina (Urukagina, ca $2355 \mathrm{eKr}$ ) valitsemisajast pärinev loomismüüdi fragment, mida tuntakse nimetusega Urukagina

${ }^{5}$ Transliteratsioon: Alster, Westenholz 1994: proloog. 
(Ukg) 15, on temaatikalt sarnane Bartoni silindri loomismüüdiga ning mõlemad kuuluvad suure tõenäosusega samasse mütoloogiakoolkonda - nende autoriks on preesterkond, kes jagas sarnaseid vaateid vähemalt maailma tekkimise osas. Savitahvel, millel järgnev tekst on kirjas, ei ole samuti säilinud täies ulatuses ning seetõttu ei ole ka võimalik täpsemalt öelda, mis on olnud kogu müüdi sisuks:

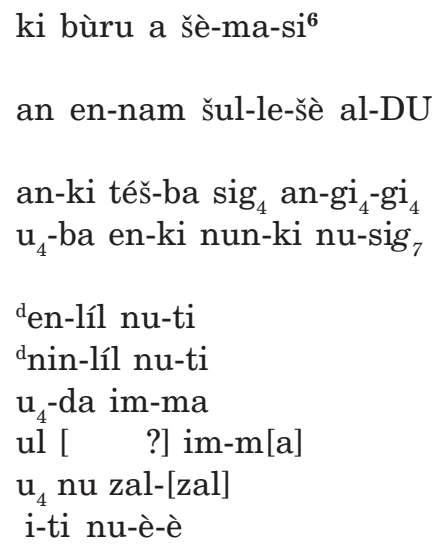

Auk maa sees on täitunud seemnega

An on isand, noore

kangelase kombel seisab

An ja Ki ühtes, nad karjuvad

Sel päeval Enki (ja) Nunki

ei ole elus (veel)

Enlil ei ole elus (veel)

Ninlil ei ole elus (veel)

Täna, eelmisel päeval

Rõõm [ ] enne

Päev ei möödu

Kuukiired ei lähe välja.

Sumeri keeles on nii seemne kui ka vee ja seega ka vihma tarbeks kasutusel üks sõna - a. Kirjeldatud on suure tõenäosusega seda, kuidas taeva ja selle jumaluse An'i seeme vihma kujul satub maa ehk Ki sisse ja Ki jääb sellest rasedaks. Lõpus on aga kujundlikult mainitud, et suguakti toimumise hetkeks ei ole veel sündinud Sumeri jumalused Su'en ja Utu.

\section{„ENKI JA NINMAH““}

Eelnevates sumeri tekstides esinevad meessoost An ja naissoost Ki - taevas ja maa. Mõlemad kontseptsioonid on ühtlasi nii isikustatud jumalused kui ka inimese jaoks tajutavad universumiosad. An esineb uus-sumeri müütides kui jumalate nõukogu pealik, kes ei sekku otseselt inimmaailma ja ka aktiivsete jumaluste asjatoimetusse. Uus-sumeri mütoloogias on keskseteks aktiivseteks kujudeks aga juba peajumalused Enlil ja Enki. Ki on küll vanemas sumeri mütoloogia kihis olnud suure tõenäosusega suur ja kõikjal levinud viljakus- ja emajumalus, kuid tema kuju ja omadused on hilisemas ja üha mehekesksemaks muutuvas mütoloogias killustunud väiksemateks viljakusjumalannadeks, kelle seas on ka müüdis „Enki ja Ninmah“

${ }^{6}$ Ukg 15: 5-14: van Dijk 1965: 40; Michalowski 1998: 240; Sjöberg 2002: 230231. 
figureerivad jumalused Namma, Ninmah ja Ninhursag. Müüdi „Enki ja Ninmah" puhul on raske öelda, kas An ja Ki on siin üldse mõeldud isikustatud jumalustena või kujutletakse neid lihtsalt kui loodusnähtusi:

$$
\begin{aligned}
& \left.\mathrm{u}_{4} \text { re-a-ta } \mathrm{u}_{4} \text { an ki-bi-ta ba-an-[... }\right]^{7} \\
& \mathrm{gi}_{6} \text { re-a-ta } \mathrm{gi}_{6} \text { an ki-bi-ta b[a-...] } \\
& \text { [mu re]-a-t[a] mu nam b[a-tar-ra-ba] } \\
& \text { [da-n] un-na-ke }{ }_{4} \text {-ne ba-tu-ud-da-a-ba } \\
& 5 \text { dama-dinana nam-NIR.PA-šè ba-tuku-a-ba } \\
& \text { dama-dinana an ki-a ba-hal-hal-la-a-ba } \\
& \text { dama-dinana [x x] ba-a-peš ù-tu-da-a-ba } \\
& \text { digir } \text { kurum }_{6} \text {-ma-bi A x x unú?-bi-šè ba-ab-kešé-a-<ba> }
\end{aligned}
$$

$1 \quad$ Neil kaugeil päevil, päeval, mil taevas maast [lahutati?]

Neil kaugeil öil, ööl, mil taevas maast [lahutati?]

Neil kaugeil aastail, aastal, mil maailmakord paika pandi ${ }^{8}$

Siis kui Anunna jumalad ${ }^{9}$ sündisid

Siis kui emajumalad võeti naiseks ${ }^{10}$

Siis kui emajumalad taevasse ja maale ära jaotati

Siis kui emajumalad [...] jäid rasedaks ja sünnitasid

Siis kui jumalad toiduportse templitesse viima kohustatud olid $(?)^{11}$

7 „Enki ja Ninmah“ 1-8: ETCSL 1.1.2; Benito 1969.

${ }^{8}$ Sumeri keeles nam-tar: 'korda määrama' või 'saatust paika panema'. Nam on sumeri keeles selles kontekstis 'see, mis on määratud', 'saatus', 'jumalik tahe'. Tar on sumeri verb 'lahti päästma', 'lõikama', 'otsustama', 'paika panema'. Maailmakorra ehk siis nii looduse kui inimmaailma reeglite paikapanek on sumeri mütoloogias üks keskseid nähtusi. Kõik, mida maailmas hoomata võis, oli paika pandud teatavate reeglite või tsivilisatsiooninormide kohaselt. Sumeri säärane arusaam on üllatavalt sarnane tänapäeva arusaamadega loodusseadustest või siis nn looduse seaduspärasustest. Vahe seisneb ehk selles, et sumerlaste jaoks pandi need reeglid paika jumalike jõudude poolt, tänapäevases loodusteaduslikus kontekstis aga on need sõnastanud loodusteadlased.

${ }^{9}$ Anunna jumalateks on sumeri mütoloogias nimetatud kõiki tähtsaid ja vanema generatsiooni jumalusi.

${ }^{10}$ Lause sisu ei ole täpselt mõistetav. Oletada võib, et viidatakse taeva ja maa lahknemise tulemusel sündinud tähtsate Anunna jumaluste abielule, mis teeb võimalikuks juba ka noorema põlvkonna jumaluste sünni.

${ }^{11}$ Kuigi kogu rida ei ole täies mahus säilinud, peaks mõte seisnema selles, et noorem põlvkond jumalusi pidi viima vanadele jumalustele nende templitesse süüa. 
Müüdi „Enki ja Ninmah“ puhul on erinevuseks võrreldes eelneva varadünastilise mütoloogiaga see, et suure tõenäosusega on kirjeldatud kuidas taevas ja maa viiakse üksteisest lahku. Ometi ei ole kuskil mainitud seda, kes võiks olla taeva ja maa lahkuviija või siis looja. Ükski varasem ega ka hilisem sumeri müüt ei maini kunagi asjaolu, nagu oleks võinud taeval ja maal olla eraldi loojajumalus. Sellised ideed väljenduvad esmakordselt alles Babüloni loomiseeposes „Enuma eliš“12 (ca 1000 eKr), kus loojajumaluseks on Babüloni linna jumal Marduk. Hilisemas Iisraeli usundis saab Vana Testamendi Genesise lugudes taeva ja maa loojaks jumal JHWH.

\section{„GILGAMEŌ, ENKIDU JA ALLILM““}

Seda, mil moel eri maailmasfäärid tekkisid, näitab väga kujukalt sumeri müüt-eepos ${ }^{13}$ „Gilgameš, Enkidu ja allilm“. Üpriski selgelt on kirjeldatud An’i ja Ki omavahelist lahknemist, kuigi selles tekstis ei ole kosmilist abielu otse välja toodud. Huvitav on veel see, et siin võtab isikustatud taevajumalus An endale elupiirkonnaks taeva: $\mathrm{u}_{4}$ an-né an ba-an-de ${ }_{6}-\mathrm{a}-\mathrm{ba}$, Enlilile, ühele sumeri peajumalustest, jääb aga elupaigaks Ki ehk maa. Allilm Kur antakse jumalanna Ereškigalile:

$$
\begin{aligned}
& \mathrm{u}_{4} \text { re-a } \mathrm{u}_{4} \text { sù-rá re-a }{ }^{14} \\
& \text { gi }_{6} \text { re-a gi }{ }_{6} \text { ba } \text { }_{9} \text {-rá re-a } \\
& \text { mu re-a mu sù-rá re-a } \\
& \mathrm{u}_{4} \text { ul nì-du } \mathrm{du}_{7} \text {-e pa è-a-ba } \\
& \mathrm{u}_{4} \text { ul nì-du } \mathrm{d}_{7} \text {-e mí zi du }{ }_{11} \text {-ga-a-ba } \\
& \text { èš kalam-ma-ka ninda šú-a-ba } \\
& \text { imšu-rin-na kalam-ma-ka nì-tab ak-a-ba } \\
& \text { an ki-ta ba-da-ba }{ }_{9} \text {-rá-a-ba } \\
& \text { ki an-ta ba-da-sur-ra-a-ba } \\
& \text { mu nam-lú-ùlu ba-an-gar-ra-a-ba }
\end{aligned}
$$

12 Eesti keeles: Annus 2003.

${ }^{13}$ Tavaliselt nimetatakse sumeri lugusid Gilgamešist, Lugalbandast ja Enmerkarist eeposteks või siis eepilisteks lugudeks, lugusid, kus on mainitud ainult jumaluste tegutsemisi, aga müütideks. Selline vahetegemine sumeri kirjanduse puhul tundub meelevaldne. Need lood on kõik oma olemuselt ja ülesehituselt sarnased ning ka kunagiste ajalooliste kuningate tegude kirjeldustes kajastatakse neid kuningaid pigem jumalike suurustena. Sumeri kirjutajad tõenäoliselt ei leidnud, et tegu oleks eri kategooriatesse kuuluvate kirjandusvormidega - seega kõlbaks nii eeposte kui ka müütide puhul kõige paremini eestikeelseks vasteks „lugulaul“.

${ }_{14}$ „Gilgameš, Enkidu ja allilm“ 1-13: ETCSL 1.8.1.4; Shaffer 1963. 
$\mathrm{u}_{4}$ an-né an ba-an-de $\mathrm{e}_{6}$-a-ba

den-líl-le ki ba-an-de ${ }_{6}$-a-ba

dereš-ki-gal-la-ra kur-ra sag rig $_{7}$-bi-šè im-ma-ab-rig ${ }_{7}$-a-ba

Neil päevil, neil kaugeil päevil

Neil öil, neil kaugeil öil

Neil aastail, neil kaugeil aastail

Neil muistseil päevil, mil olulised (sobivad) asjad nähtavale toodi

Neil muistseil päevil, mil olulised (sobivad) asjad tõepoolest õigelt paika pandi

Mil kogu maa pühamutes leiba süüa saadi

Mil kogu maa ahjudes tuli üles tehti

Mil An (taevas) Ki'st (maast) lahku viidi

Mil Ki (maa) An'ist (taevast) eemale viidi

Mil inimkonna nimi paika pandi (=kui inimesed loodi)

Mil An taeva enda jaoks ära viis

Mil Enlil maa enda jaoks ära viis

Mil Kur (allilm) Ereškigalile kingituseks anti

Müüt „Gilgameš, Enkidu ja allilm“jätkub juba jumal Enki tegevuse kirjeldusega ning hiljem keskendub Gilgameši kaaslase Enkidu reisile allilma. Erinevuseks võrreldes eelnevate loomislugudega on selle teksti juures see, et kirjeldatud on kahe kosmilise sfääri An'i ja Ki lahkuviimist ning selle kaudu uute kosmiliste sfääride teket, mis eri jumaluste vahel ära jaotatakse.

\section{ARUTLUSI JA TÕLGENDUSI}

Ei Lähis-Ida mütoloogias ega ka Vana Testamendi Genesise loomislugudes ei pöörata suuremat tähelepanu maailma loomise täpsemale lahtiseletamisele. Veidi pikemalt kirjeldab seda protsessi küll Babüloni loomiseepos „Enuma eliš“. Selge on aga see, et muistne inimene pidas oma olemuse ja ka inimeseks olemise seisukorra lahtiseletamiseks maailma alguspunkti määratlemist äärmiselt oluliseks. Kõik pidi kuskilt alguse saama - maailm ei olnud lihtsalt olemas - vaid pidi olema kuidagi loodud, tekkinud, kujundatud. Muistse inimese jaoks algas ka ajalugu maailma loomise hetkest - tegu oli konkreetse punktiga ajas, kust kõik alguse sai - ehk siis kohaga, kust aeg ise alguse sai. Loomise hetkest edasi hakkas aga kogu kosmos - nii loodus, taevakehad kui ka inimtsivilisatsioon oma kindlaid reegleid pidi arenema, kuni jõudis välja tänasesse päeva. Inimese enda 
tulevikuks oli aga pärast surma lahkumine allilma, kus elu toimus edasi sarnaselt maapealse inimmaailmaga, kuid oli märgatavalt raskem ja õudutekitavam. Ainult vähestele väljavalitutele, inimilmas suuri tegusid teinud valitsejatele või muudele tähtsatele isikutele sai allilmas osaks parem kohtlemine. Näiteks kuningas Gilgameš muutus hilisemas mütoloogias isegi väiksemat laadi allilmajumaluseks. Ainult ühele surelikest inimolenditest - veeuputusloo kangelasele Ziusudrale - on sumeri mütoloogia andnud ka igavese maapealse elu, kuigi see igavene elu ei erinenud olemuslikult kõikide teiste inimeste tegemistest ja toimetustest (vt Espak 2008).

Tihti on üritatud väita, et sumeri ja seega ka kogu Lähis-Ida elutunnetuses seisnes kogu maailma ideaalne seis selle maailma loomise hetkes või siis kuskil hüpoteetiliste algaegade juures, kui kõik oli alles loodud ja jumalikud reeglid omal puhtal kujul paika pandud. Selline väide ei tundu aga usutav, sest ei ole teada ühtegi Lähis-Ida teksti, mis nimetaks aegade algust kuidagi pühamaks või puhtamaks kui oma kaasaega. Pigem iseloomustab kogu Lähis-Ida mütoloogiat teatud paratamatusetunne. Kuigi ka ajaloos toimub mitmeid muudatusi, vahetuvad valitsejad ja ka jumalused võivad omandada täiesti uusi aspekte ja ülesandeid, jääb kogu maailma olemus ja toimimine siiski samaks. Aja kuluga ei suurene ei kaos ega korratus, kuigi vahel ohustavad kogu tsivilisatsiooni ellujäämist kõikvõimalikud deemonid või siis halbade kavatsustega jumalused. Kõikidest tsivilisatsiooni ohustavatest nähtustest saadakse aga alati võitu ja maailm jätkab oma endist toimimist vastavalt loomise alguses paika pandud reeglitele. Selline paratamatuse tunnetamine tekitas kahtlemata paljudel juhtudel lootusetusetunnet ning sellest omakorda kujunesid välja ka kõikvõimalikud uudsed mütoloogilised ideed ja mõtted. Tõenäoliselt ka veeuputusloo kangelasele Ziusudrale igavese elu andmine ja Gilgameši luhtunud katsed leida seda igavest elu on kirjanduslikud motiivid, mis on sündinud just soovist leida lunastust immanentsest kosmosest, mis oli lahtimõtestatav ainult geograafilises plaanis ning ei jätnud inimesele muud võimalust, kui surma järel asuda elama ebameeldivusi täis allilma.

Esimest korda kohtab Lähis-Idas tekste, mis pakuvad inimesele väljapääsu geograafilisest maailmast, eelkõige Iisraeli usundis, mida tunneme praegu ainult Vana Testamendi vahendusel. Kuna ükski Vana Testamendi tekst ei ole täpselt dateeritav ja oma autentsesse konteksti tagasipaigutatav, ei ole aga ka kahjuks teada see, mil moel või milliste mõjutuste kaudu selline uus Iisraeli transtsendentset väge JHWH't propageeriv usund oma alguse sai. Lähis-Ida mütoloogia paratamatusest pakub aga esimese konkreetse väljapääsu alles kristlik liikumine, mis avab inimesele tee maa, taeva ja taevakehade maailmast kuhugi teise maailma transtsendentse jumala või siis selle jumala vaimu juurde. Lähis-Ida vanemas 
mütoloogias oli alguses taevas An ja maa Ki, kes sünnitasid omakorda Kuu ja Päikese. Genesise lugude kohaselt olid need taevas ja maa ning ka kõik muud taevakehad kõigest elutud ja JHWH poolt loodud asjad. Johannese evangeeliumi alguses olev ja kahtlemata ka gnostilisi sugemeid kandev varakristlik „loomismüüt“ on ehk parimaks näiteks Lähis-Ida mütoloogia (või õigemini mütoloogilisest maailmapildist vabastatud mõttemaailma) kõrg- ja lõpp-punktist kristluses:

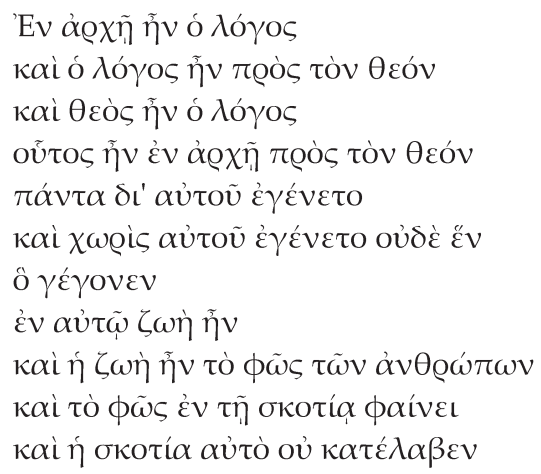

\author{
Alguses oli sõna \\ ja sõna oli Jumala juures \\ ja Jumal oli sõna \\ See oligi alguses Jumala juures \\ Kõik tema läbi on tekkinud \\ ja ilma temata tekkinud ei ole midagi \\ mis tekkinud on \\ Temas oli elu, \\ ja elu oli inimestele valguseks \\ Ja valgus paistab pimeduses \\ ja pimedus ei ole seda omaks võtnud
}

Kuigi hilisemas kristluses jäi püha tekstina käibele ka sumerlike sugemetega Genesise maa ja taeva loomise müüt, domineerib kristlike mõtlejate peades juba see uus müüt, mis ei loe algupunktiks enam taevakehasid ja nende tekkimist või loomist, vaid näeb maailma olemise taga juba selliseid nähtusi nagu sõna, valgus ja elu. Kui Ziusudra sai omale igavese elu inimmaailmas, siis Jeesus sai omale igavese elu selle elu tekitaja juures, ehk teda kujutatigi kui elu, valgust või sõna ennast. Inimese ja ka jumala olemus ei ole enam kinni nähtavates asjades ja geograafilises plaanis mõõdetav, vaid inimene ja tema teadvus on saanud uue tähenduse.

Tänapäeva üldkehtivaks loomismüüdiks võib ilma kahtluseta pidada teooriat Suurest Paugust, mille kohaselt kosmos sai alguse $c a 14$ miljardit aastat tagasi mingi seletamatu alguspunkti „plahvatusest“. Hilisemast osakeste liitumisest tekkis tänapäevane mateeria, moodustades pikapeale tähti, galaktikaid ja planeete. Selle plahvatuse jõul kosmos aga laieneb edasi kuni raugemiseni. Võimalik, et siis algab jällegi kõik uuesti. Universumi algushetkede, algosakeste ja nende tekkimise kohta loodetakse saada lisateavet Euroopa Tuumauuringute Organisatsiooni käivitatud osakestekiirendi mõõtetulemuste kaudu. Kuid ka siis, kui oleks võimalik leida nimetused kõikidele mõeldavatele algosakestele ja seletada lahti nende tekkimisja liitumisprotsessid, jääks selle protsessi kirjeldus kõigest mütoloogiaks, 
mis on ainult pisut objektiivsem ja täpsematele vaatlusandmetele tuginev, kui olid seda kõige varajasemad sumeri müüdid - iga uus faas maailma tekkimise või olemise seletamiseks on ühtlasi ka uus faas mütoloogilise maailmapildi arengus. Kui Sumeris kirjatundjad mõistsid, et taevast allasadanud vihm muudab maa rasedaks ehk viljakandvaks, ei eksinud nad ju milleski olulises, sest üldises plaanis ju nii ongi. Samamoodi peegeldab tänapäeva füüsika meile asjade nähtavat ja reaalset seisu - tegemist ei ole mitte väljamõeldisega, vaid vaatlusandmete kogumisel ja analüüsimisel saadud järeldustega. Teisalt on jällegi tegu mütoloogiaga, sest ükskõik kui palju maailma nähtustele või protsessidele ka nimesid või seletusi antaks, ei muuda need seletused mitte midagi inimese olukorras või tema saatuses. Vahe on ehk selles, et kui Lähis-Idas inimene teadis, et pärast surma jätkub tema eksistents allilmas, siis tänapäevane mütoloogia ehk loodusteadused selle küsimusega lihtsalt ei tegele ${ }^{15}$ - see uus mütoloogia ei vasta ühelegi küsimusele sellest, miks või mille tõttu mateeria säärasel kujul arenema hakkas, ega ka sellele, kuhu see areng lõpuks välja viib. Kuigi on ilmselge, et sellistele küsimustele ei leia vastust vaatlusandmete ega katsetulemuste põhjal, ei tähenda see seda, et küsimuse peaks kõrvale heitma.

Kui Lähis-Ida mütoloogiale niivõrd omane igavese elu otsimise motiiv sai vastuse uues idamaises usundis kristluses, nagu ka hinduistlik maailmanägemine sai lahenduse budismis, siis tänapäevane teaduslikuks kutsutud mütoloogia seda lahendust pakkuda ei saa - seda eelkõige oma teadusliku meetodi ainukehtivaks tunnistamise tõttu. Ükskõik kui palju midagi inimkeeles ka ei kirjeldata või seletata, on tegu siiski ainult ühe faasiga mütoloogia pidevas arengus, mida sajandite pärast uurivad juba tänapäeva usundiloolaste ja folkloristide kauged järeltulijad.

15 Inimene ja tema olemus või ka teadvus ei kuulu tänapäeval enam (loodus)teadusliku ainese uurimisalasse, kuigi sellekohane arutelu kestab küll meditsiinilises plaanis näiteks psühholoogia raames. Nii ehk ei olekski vale väita, et tänapäevane loodusteadus, mis paneb rõhku eelkõige just oma teaduslikkusele, on laiemas plaanis muutunud pseudoteaduseks - nähtuseks, mis suudab luua küll uusi tehnoloogilisi lahendusi, aga ei suuda või õigemini ei soovi enam vastata ühelegi olemuslikule küsimusele. Võib-olla on tegemist samasuguse eluhoiakuga nagu kunagises katoliku kirikus, kes keelustas Galileo Galilei ideed, mis ei sobitunud tema mütoloogiasse ning olid seetõttu hirmutavad, kuigi ilmselgelt pidi ka tollane Vatikani haritud eliit väga hästi aru saama, milline kosmose ülesehituse skeem tegelikkuses õige on. Teiste sõnadega, kui 17. sajandi kirik tundis hirmu mõõdetavuse ees, siis tänapäevane üldlevinud mütoloogiline teadusreligioon tunneb paanilist hirmu mittemõõdetavuse ees. 


\section{KIRJANDUS}

Alster, Bent; Aage Westenholz 1994. The Barton Cylinder. - Acta Sumerologica Japonensia 16, pp. 15-46.

Annus, Amar (tlk ja eessõna) 2003. Enuma eliš: Babüloonia loomiseepos. Tallinn: Kirjastuskeskus.

Benito, Carlos Alfredo 1969. „Enki and Ninmah“ and „Enki and the World Order“. PhD dissertation. Philadelphia: University of Pennysilvania.

Clifford, Richard J. 1994. Creation Accounts in the Ancient Near East and the Bible. The Catholic Biblical Quarterly Monograph Series 26. Washington DC.

ETCSL = J. A. Black, G. Cunningham, J. Ebeling, E. Flückiger-Hawker, E. Robson, J. Taylor, G. Zólyomi. The Electronic Text Corpus of Sumerian Literature. University of Oxford 1998ff. http://www-etcsl.orient.ox.ac.uk/

van Dijk, Jan 1965. Le motif cosmique dans la pensée sumérienne. - Acta Orientalia 28 , pp. $1-59$.

van Dijk, Jan 1976. Existe-t-il un „Poème de la Création“ sumérien? - Alter Orient und Altes Testament 25, pp. 125-133.

Dietrich, Manfried 1995. ina ūmī ullūti, An jenen (fernen) Tagen. - Alter Orient und Altes Testament 240, S. 57-72.

Espak, Peeter 2005. Urukagina 15 - vanasumeri loomismüüdi fragment 24. sajandist eKr. - Verbum Habet Sakala 2004: täiendusköide. Tartu, lk 47-49.

Espak, Peeter 2008. Passing to the Underworld in Sumerian Texts. - Forschungen zur Anthropologie und Religionsgeschichte 42, pp. 67-71.

Espak, Peeter 2009. Mesopotaamia kosmiline geograafia ja Abzu: Päikesejumala reis allilma. - Eesti Akadeemilise Orientaalseltsi aastaraamat 2008. Tartu, lk. 19-29.

Espak, Peeter 2009. The God Enki in Sumerian Royal Ideology and Mythology. Dissertationes Theologiae Universitatis Tartuensis 19. Tartu Ülikooli Kirjastus 2010.

Horowitz, Wayne 1998. Mesopotamian Cosmic Geography. Mesopotamian Civilizations 8. Winona Lake: Eisenbrauns.

Michalowski, Piotr 1998. The Unbearable Lightness of Enlil. - Intellectual Life of the Ancient Near East. Papers Presented at the 43rd Rencontre assyriologique internationale Prague, July 1-5, 1996. Ed. by Jiri Prosecky. Prague: Oriental Institute, pp. 237-248.

Shaffer, Aaron 1963. Sumerian Sources of the Tablet XII of the Epic of Gilgames. $\mathrm{PhD}$ dissrertation. Philadelphia: University of Pennsylvania.

Sjöberg, Åke W. 2002. In the Beginning. - Riches Hidden in Secret Places: Ancient Near Eastern Studies in Memory of Thorkild Jacobsen. Ed. by Tzvi Abusch. Winona Lake: Eisenbrauns, pp. 229-247. 


\section{Summary}

\section{MIDDLE EASTERN LEGENDS ABOUT THE CREATION OF COSMOS}

The paper discusses different known creation accounts from the Sumerian literature describing how the heaven and earth and also other celestial bodies were created in the minds of ancient mythographers. The texts analysed include The Barton Cylinder, Urukagina 15, Enki and Ninmah, and Gilgameš, Enkidu and the Netherworld.

It is explained that the Sumerians had no separate myths or longer pieces of literature directly describing the act of creation. Creation of heaven and earth was usually mentioned in the beginning of a longer mythological text of different thematical contents as a literary introduction for that myth. The creation of „the present world“ usually takes place by the copulation of An and Ki (heaven and earth) resulting in Ki getting pregnant and giving birth to all the other major Sumerian gods and celestial bodies. The Sumerian myth-epic Gilgamesh, Enkidu and the Netherworld describes how the different spheres of universe were divided between different Sumerian gods.

The paper concludes in comparing the Sumerian accounts of creation with the similar motives in the Old Testament myth of Genesis. A new transcendent Near Eastern account of creation, the beginning of the Gospel of John is drawn as an example of the later developments in Ancient Near Eastern mythology. It is concluded that in its basic nature, the present theories about the Big Bang in modern day physics are also mythological in nature and they only represent one phase in the development of mythological beliefs about the creation of the cosmos.

KEY WORDS: Sumerian mythology, Ancient Near Eastern religions, myths of creation, Sumerian Enki and Ninmah, Gilgamesh, Enkidu and the Netherworld, the Barton Cylinder, Ukg 15 